\title{
A microstructural characterization of some Late Bronze Age metals from Fraga dos Corvos site: fibula, pendants, riveted sheet and droplet
}

\author{
F. Lopes*, R.J. Silva**, E. Figueiredo****, M.F. Araújo*, J. Reprezas***, E. Luís*** and J.C. Senna- \\ Martinez*** \\ *IST/ITN, Instituto Superior Técnico, Universidade Técnica de Lisboa, Estrada Nacional 10, 2686-953 \\ Sacavém, Portugal \\ **CENIMAT/I3N, Departamento de Ciências dos Materiais, Faculdade de Ciências e Tecnologia da \\ Universidade Nova de Lisboa, 2829-516 Caparica, Portugal \\ ***Centro de Arqueologia, UNIARQ, Universidade de Lisboa, Alameda da Universidade, 1600-214 Lisboa, \\ Portugal
}

The knowledge of our pre-history and ancient metal artefacts production methods can only be deeply investigated through the multidisciplinary approaches involving different analytical techniques including microscopy techniques. The present study concerns the elemental and microstructural characterization of prehistoric bronze artefacts from the Northwestern Iberia Peninsula. During Bronze Age an increment of metal artefacts production and its typological diversification is observed related to the development of metallurgical technology. Several artefacts have been found during recent excavations at the Bronze Age settlement of Fraga dos Corvos (Macedo de Cavaleiros, Portugal) [1,2]. The analysis of metallurgical remains points out to the existence of local metallurgical activities. Five bronze artefacts previously analysed by micro-EDXRF [3], an Acebuchal fibula fragment, two pendants and a riveted sheet (probably a fragment of a vessel or cauldron) with average concentration values of $10 \pm 1.1 \% \mathrm{Sn}$ and $\sim 2 \pm 0.5 \% \mathrm{~Pb}$ and a droplet (?) with $\sim 5 \% \mathrm{Sn}$ and $\sim 4 \% \mathrm{~Pb}$, were selected for optical microscopy (OM) and SEM-EDS analysis.

Microscopy observations showed to be very important for the comprehension of pre-historic bronze metallurgy, allowing the identification of different phases, inclusions and thermomechanical processes applied during artefacts production. The fibula and the pendants show an equiaxed and twinned microstructure with slip bands (Figure 1 (a) and (c)). The characteristics observed are related to recrystallized and plastically deformed $\alpha-\mathrm{Cu}$ structures. These features indicate that the artefacts were hammered and annealed (thermomechanical cycling), ending with a hammering operation. The pendants only exhibit slip bands near the surface, probably resulting from a finishing operation. Lead and $\mathrm{Cu}-\mathrm{S}$ inclusions are frequently observed. The riveted sheet has an annealed microstructure with large $\alpha-\mathrm{Cu}$ grains, undissolved $(\alpha+\delta)$ eutectoid and few annealing twins. Elongated $\mathrm{Cu}-\mathrm{S}$ inclusions, lead globules and pores were identified by SEM-EDS (Figure 1 (a)). Its microstructure indicates that shaping was obtained by just one or few thermomechanical cycles. The droplet presents a coarse and cored dendritic structure (Figure 1 (b)). Rounded $\mathrm{Cu}-\mathrm{S}$ inclusions, lead globules and pores were also observed. Those are characteristics of a slow cooled as-cast alloy. Due to its low Sn content the $(\alpha+\delta)$ eutectoid is absent. As a final note, microscopy techniques allowed establishing the manufacture processes involved in bronze metallurgy and to conclude that different thermomechanical processes were applied according to the typology of the artefact.

\section{References}

1. Senna-Martinez J.C. and Luís E., Cadernos Terras Quentes 6:69, 2009.

2. Senna-Martinez J.C. and Luís E., Cadernos Terras Quentes 8:33, 2011.

3. Senna-Martinez J.C. et al., O Arqueólogo Português 2012 (in press). 

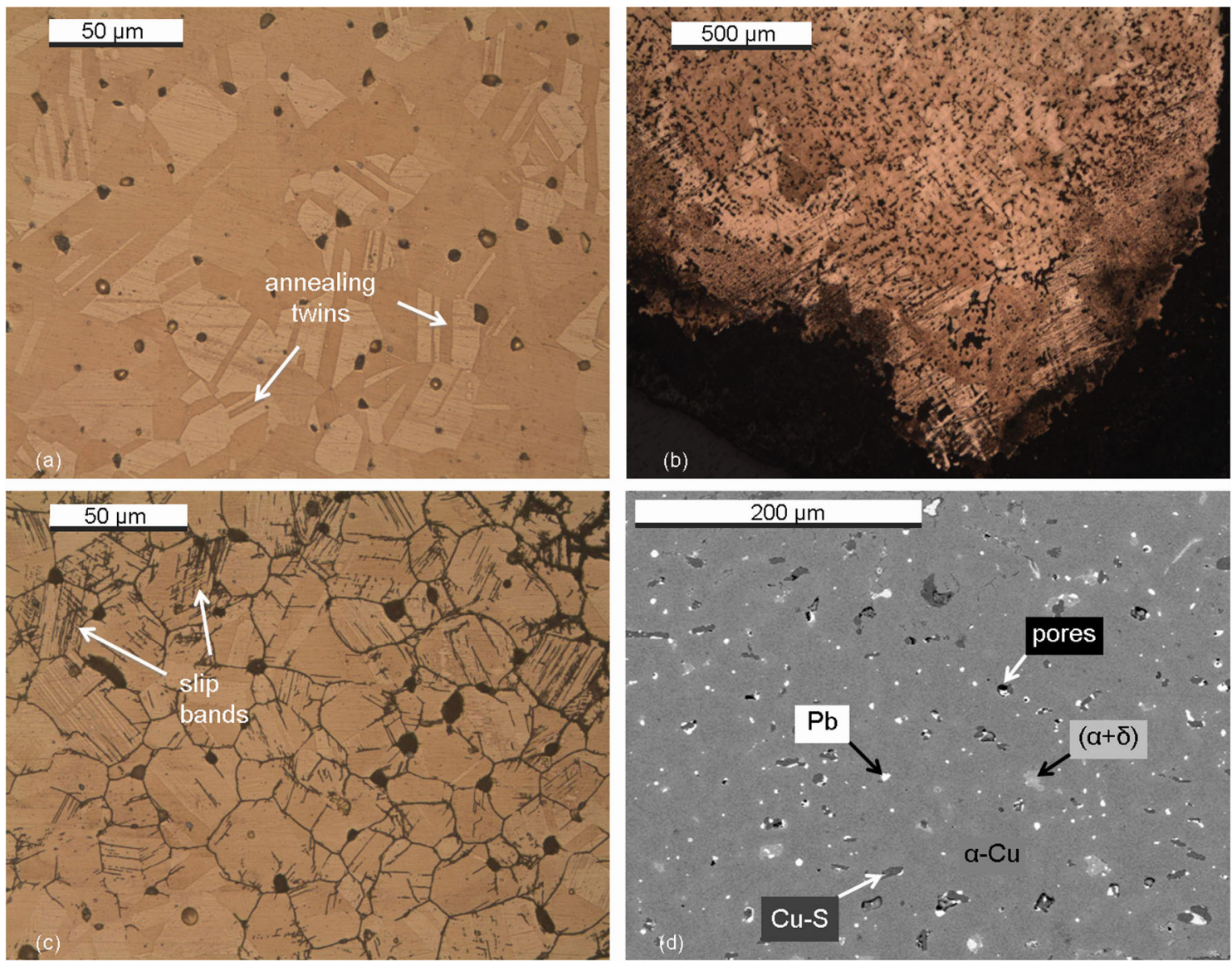

Figure 1. MO images of (a) fibula microstructure showing annealing twins, (b) droplet showing fine dendritic structure and (c) pendant showing slip bands. SEM image (d) riveted sheet showing $\alpha$-Cu matrix with $(\alpha+\delta)$ eutectoid, copper sulphides (Cu-S), lead inclusions and pores identification.

Financial support received from the Portuguese Science and Technology foundation under the EarlyMetal project PTDC/HIS-ARQ/110442/2008 and the grants SFRH/BPD/73245/2010 (EF) and SFRH/BD/72369/2010 (EL). Financial support of CENIMAT/I3N through the Strategic Project LA25/2011-2012 (PEstC/CTM/LA0025/2011) is gratefully acknowledged. 